\title{
Identification of Grape (Vitis) Rootstocks Using Sequence Characterized Amplified Region DNA Markers
}

\author{
Hong Xu1 and Alan T. Bakalinsky ${ }^{2}$ \\ Department of Food Science and Technology, Wiegand Hall, Oregon State \\ University, Corvallis, OR 97331-6602
}

\begin{abstract}
Five sequence characterized amplified region (SCAR) DNA markers were reevaluated at substantially higher annealing temperatures than originally reported; four were polymorphic among nine rootstocks tested. Four new informative SCAR markers also are reported, based on redesigning primers from previously cloned random amplified polymorphic DNA (RAPD) markers. Based on the eight polymorphic markers, rootstocks MG 420A, MG101-14, Richter 99, Couderc 3309, and Kober 5BB were distinguishable. Riparia Gloire and Couderc 1616 could be distinguished from the others, but not from one another, and $\mathrm{SO} 4$ and $5 \mathrm{C}$ also could be distinguished from the others, but not from one another.
\end{abstract}

Traditional methods of identifying grape cultivars have relied on morphological characters whose expression is affected by developmental and environmental factors. Limited polymorphism has hampered the use of biochemical markers such as isozymes (Parfitt and Arulsekar, 1989; Subden et al., 1987). The need for practical and objective means for identifying grape cultivars has encouraged researchers to investigate DNA-based techniques (Botta et al., 1995; Bourquin et al., 1993, 1995; Bowers et al., 1993; Guerra and Meredith, 1995; Striem et al., 1990; Thomas et al., 1994). We recently generated six polymer chain reaction (PCR) markers from cloned random amplified polymorphic DNA (RAPD) fragments for identifying winegrape rootstocks (Xu et al., 1995). The markers were designed as sequence characterized amplified region (SCAR) DNA markers (Paran and Michelmore, 1993), and three of the six were found to be informative. The SCAR markers were developed because the original RAPDs were not sufficiently reproducible for use in genetic typing. Here, five of the SCAR markers have been reevaluated at substantially higher annealing temperatures, and four were polymorphic among the nine rootstocks tested. Further, four new informative SCAR markers

Received for publication 3 Aug. 1995. Accepted for publication 3 Jan. 1996. Technical paper no. 10,793 of the Oregon Agricultural Experiment Station. We gratefully acknowledge the financial support of the Pacific Northwest Center for Small Fruits Research and the Oregon-Massachusetts Biotechnology Partnership and thank S. Arulsekar for reviewing the manuscript. The cost of publishing this paper was defrayed in part by the payment of page charges. Under postal regulations, this paper therefore must be hereby marked advertisement solely to indicate this fact.

${ }^{1}$ Current address: Oregon Health Sciences Univ., 3375 SW Terwilliger Blvd., Casey Eye Institute, CE-RES, Portland, OR 97201.

${ }^{2}$ To whom reprint requests should be addressed Phone: 541/737-6510; fax: 541/737-1877; e-mail bakalina@bcc.orst.edu. also are described, based on redesigning primers from the previously cloned RAPD fragments.

The reliability of RAPD markers has been subject to controversy. Workers have shown that the RAPD assay is unusually sensitive to changes in reaction conditions and that the banding patterns are DNA polymerasedependent (discussed in Xu et al., 1995). To overcome these difficulties, sequence-specific, RAPD-derived markers, such as SCARs (Paran and Michelmore, 1993) and allele-specific associated primers (ASAPs) (Yu et al., 1995), have been developed. This approach was found useful in the present study.

\section{Materials and Methods}

Rootstock origins (Galet, 1979) are MG 420A (Vitis berlandieri $\times$ V. riparia), Richter 99 (V. berlandieri $\times \quad V$. rupestris), 5C $(V$. berlandieri $\times$ V. riparia), $\mathrm{SO} 4$ ( $V$. berlandieri x V.riparia), Couderc 3309 (V. riparia tomentose $\times$ V. rupestris), MG 101-14 (V. riparia $\mathrm{X}$ $V$. rupestris), Couderc 1616 [V. solonis (riparia-rupestris-candicans) $\times$ V . riparia], Kober 5BB ( $V$. berlandieri selection), and Riparia Gloire (V. riparia selection). DNA extraction procedures, RAPD PCR amplification conditions, agarose gel electrophoresis, cloning of RAPD markers, DNA sequencing, and design of sequence-specific primers have been described (Xu, 1995; Xu et al., 1995). Southern hybridization analysis confirmed that the correct RAPD fragments had been cloned (data not shown for marker OPG05 ${ }_{1420}$ ) (Xu et al., 1995). Each marker is designated by the name of the original RAPD primer $(\mathrm{UBC}=$ Univ. of British Columbia, $\mathrm{OP}=$ Operon Technologies), followed by the size of the SCAR fragment (subscript). The corresponding SCAR primers are designated similarly with a $\mathrm{U}$ (upper) or L (lower), and sometimes a number, following the subscript. Annealing temperatures were chosen empirically and were 11 to $13 \mathrm{C}$ higher than the optima suggested by computer analysis (Oligo version 4.0; National Biosciences, Plymouth, Minn.). The five markers, UBC20 $4_{1140}$, UBC2 $21_{1840}$, UBC231 1660 , UBC251 $1_{1440}$, and OPG05 ${ }_{500}$, are the same as in Xu et al. (1995), except that the latter is designated $\mathrm{OPG} 05_{550}$ in the earlier publication, and all were evaluated in the present study at higher than the original annealing temperatures. Markers $\mathrm{OPG} 6_{1440}$ and OPG02 $2_{1320}(\mathrm{Xu}$ et al., 1995) were evaluated using newly designed internal primers. Marker OPG02 ${ }_{430}$ is half the size of the original marker, $\mathrm{OPG}_{260}$, (Xu et al., 1995) because the new internal primers generate a significantly smaller fragment. Marker OPG05 ${ }_{1420}$ has not been described before.

PCR mixtures contained $10 \mathrm{~mm}$ Tris- $\mathrm{HCl}$, $50 \mathrm{~mm} \mathrm{KCl}, \mathrm{pH} 9.0,0.1 \%$ Triton X-100, 1 unit of Taq DNA polymerase (Promega Corp., Madison, Wis.), $100 \mu \mathrm{M}$ of each dNTP, $0.2 \mu \mathrm{M}$ of each primer, $1.5 \mathrm{~mm} \mathrm{MgCl}_{2}$, and $\approx 5 \mathrm{ng}$ genomic DNA in a final volume of $20 \mu \mathrm{l}$. Reaction mixtures were overlaid with mineral oil (E.R. Squibb \& Sons, Princeton, N.J.) in an EasyCycler thermocycler (Ericomp, San Diego) and heated for $5 \mathrm{~min}$ at $94 \mathrm{C}$, followed by 35 cycles of $30 \mathrm{sec}$ at $94 \mathrm{C} ; 1 \mathrm{~min}$ at the annealing temperatures specified in Table 1 , and $2 \mathrm{~min}$ at $72 \mathrm{C}$; followed by a final $5 \mathrm{~min}$ at $72 \mathrm{C}$. All reaction mixtures were prepared in a laminar flow hood, and control reactions containing all components, except genomic DNA, were performed with each set of amplifications. After amplification, about half of each reaction product was electrophoresed, and the agarose gels were stained with ethidium bromide and viewed on an ultraviolet transilluminator.

\section{Results and Discussion}

Nine sequence-specific primer pairs derived from nine cloned RAPD markers were evaluated (Tables 1 and 2). Primer pairs OPG05 ${ }_{1420} \mathrm{U} / \mathrm{L}, \mathrm{UBC} 231_{1840} \mathrm{U} 2 / \mathrm{L} 2$, and $\mathrm{UBC} 251_{1440} \mathrm{U} / \mathrm{L}$ generated a product only from the rootstocks from which the original RAPD markers had been cloned, giving rise to markers specific to MG101-14, Richter 99, and Couderc 3309, respectively. Primer pairs OPG02 $2_{1320} \mathrm{U} / \mathrm{L}, \quad \mathrm{UBC} 231_{1660} \mathrm{U} / \mathrm{L}$, and $\mathrm{OPG} 6_{1440} \mathrm{U} / \mathrm{L}$ gave rise to products from rootstocks in addition to those from which the original RAPD markers had been cloned. Nevertheless, the results were polymorphic and, thus, informative. Amplifications involving primer pairs $\mathrm{OPG} 02_{430} \mathrm{U} 2 / \mathrm{L} 2$ and $\mathrm{OPG} 05_{500} \mathrm{U} /$ $\mathrm{L}$ also generated amplification products from rootstocks, in addition to those from which the original RAPD markers had been cloned. However, they also generated apparent length variants that provided additional polymorphisms. Although Southern analysis established homology among the variants and the expected bands (data not shown), allelism could not be demonstrated for lack of a pedigree. Amplification using primer pair UBC204 ${ }_{1140} \mathrm{U} / \mathrm{L}$ resulted in a loss of polymorphism because all rootstocks gave rise to the formerly polymorphic RAPD band. However, this marker may still have utility because it may be polymorphic among rootstocks not tested in this study. 
Table 1. Sequence-specific primer pairs derived from cloned RAPD markers. ${ }^{2}$

\begin{tabular}{|c|c|c|c|}
\hline Code $^{y}$ & Primer pairs & Sequence (5'-3') & Annealing temp $\left({ }^{\circ} \mathrm{C}\right.$ \\
\hline \multirow[t]{2}{*}{$\overline{1}$} & $\mathrm{OPG}^{2} 2_{430} \mathrm{U} 2$ & GAA TCG TCA GAG CCA TAA CC & 66 \\
\hline & $\mathrm{OPG} 02_{430} \mathrm{~L} 2$ & ATT GCC TAA CAC TGT CCA AG & \\
\hline \multirow[t]{2}{*}{2} & $\mathrm{OPG} 02_{1320} \mathrm{U}$ & GAT TAG GAG TTG TGG GAT GA & 64 \\
\hline & OPG02 ${ }_{1320} \mathrm{~L}$ & AGG TGT AGC CTC AAT GAG AA & \\
\hline \multirow[t]{2}{*}{3} & 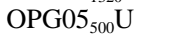 & CTG AGA CGG AGA GCT AAA AAA TAA & 60 \\
\hline & OPG $05_{500} \mathrm{~L}$ & 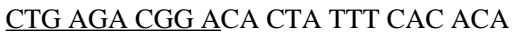 & \\
\hline \multirow[t]{2}{*}{4} & $\mathrm{OPG}_{0} 5_{1420} \mathrm{U}$ & AAA TCA CGG CCA ATC TTG TC & 70 \\
\hline & $\mathrm{OPG}_{0}{ }_{1420} \mathrm{~L}$ & GGG CCT AAA GCT GGT CAT TC & \\
\hline \multirow[t]{2}{*}{5} & $\mathrm{UBC}_{20} 4_{1140} \mathrm{U}$ & TTC GGG CCG TGT CAC ATG AAT TCC & 66 \\
\hline & $\mathrm{UBC} 204_{1140} \mathrm{~L}$ & TTC GGG CCG TTG ACT TTG AGG CAA & \\
\hline \multirow[t]{2}{*}{6} & $\mathrm{UBC} 231_{1840} \mathrm{U} 2$ & ACC GGT ATG GTA CAG ATG CT & 62 \\
\hline & $\mathrm{UBC} 231_{1840} \mathrm{~L} 2$ & GGG AGT TCC AAC AAG ATT TA & \\
\hline \multirow[t]{2}{*}{7} & $\mathrm{UBC} 231_{1660} \mathrm{U}$ & TCC ACG GAC GGG TTG GGA TAG ATT & 66 \\
\hline & $\mathrm{UBC} 231_{1660} \mathrm{~L}$ & TCC ACG GAC GAA TTC CAG GGG GTC & \\
\hline \multirow[t]{2}{*}{8} & $\mathrm{UBC} 251_{1440} \mathrm{U}$ & CTT GAC GGG GTA TGC TGG GCT GAG & 66 \\
\hline & $\mathrm{UBC} 251_{1440} \mathrm{~L}$ & CTT GAC GGG GGA GGG TTT GAA & \\
\hline \multirow[t]{2}{*}{9} & $\mathrm{OPG} 6_{1440} \mathrm{U}$ & GAT TGA GGT AAC TTG ACT GA & 62.5 \\
\hline & $\mathrm{OPG}_{06}{ }_{1440} \mathrm{~L}$ & GTT AGG TGG AAA GAT GAA AG & \\
\hline
\end{tabular}

${ }^{2}$ The subscripts preceeding the "U" (upper) and "L" (lower) indicate the size of the marker in base pairs. ${ }^{y}$ Numbers used to identify primers in Table 2 . Underlined sequences are derived from the original RAPD primers. OPG05 $5_{500} \mathrm{U} / \mathrm{L}$ was designated $\mathrm{OPG} 05_{550} \mathrm{U} / \mathrm{L}$ in Xu et al. (1995).

Table 2. Grape rootstock-sequence characterized amplified region (SCAR) marker matrix.

\begin{tabular}{|c|c|c|c|c|c|c|c|c|c|}
\hline \multirow[b]{2}{*}{$\underline{\text { Rootstock }}$} & \multicolumn{9}{|c|}{ SCAR primer pairs $^{\mathrm{z}}$} \\
\hline & 1 & 2 & 3 & 4 & 5 & 6 & 7 & 8 & 9 \\
\hline$\overline{\mathrm{MG} 420 \mathrm{~A}}$ & $+/+/+^{y}$ & & $+/+^{x}$ & & + & & & & \\
\hline Richter 99 & + & \pm & + & & + & \pm & + & & + \\
\hline Couderc 3309 & & $\overline{+}$ & + & & + & & & \pm & \\
\hline MG 101-14 & & + & + & \pm & + & & & & + \\
\hline Kober 5BB & & & $+1+^{x}$ & & + & & + & & + \\
\hline SO4 & + & & + & & + & & + & & + \\
\hline $5 \mathrm{C}$ & \pm & & + & & + & & \pm & & \pm \\
\hline Riparia Gloire & & & + & & + & & & & \\
\hline Couderc 1616 & & & + & & \pm & & & & \\
\hline
\end{tabular}

${ }^{2}$ Refer to Table 1 for sequences of the coded primers. " + " indicates the presence of the marker when rootstock DNA was used in an appropriate DNA amplification reaction. " \pm " (underlining) indicates that the original RAPD marker was cloned from the specified rootstock. Internal sequence-specific primers derived from a monomorphic RAPD fragment of $922 \mathrm{bp}$ cloned from SO4 generated the predicted band of $650 \mathrm{bp}$ in all rootstocks at an annealing temperature of $64 \mathrm{C}$. The primer sequences are (5'-3') UBC234 ${ }_{650} \mathrm{U} 1$, CTC CCA CAC TTT CAG ACA AC and UBC234 ${ }_{650} \mathrm{~L} 1$, AAC CAT CCA TCC TAA CCA TA.

$y$ “" $+/+/+$ " indicates that in addition to the 430 -bp product, two apparent length variants of $\approx 460$ and $490 \mathrm{bp}$ were amplified.

${ }^{x "}+/+"$ indicates that in addition to the 500-bp product, an apparent length variant of $\approx 550$ bp was amplified.

Based on the eight polymorphic markers, rootstocks MG 420A, MG101-14, Richter 99, Couderc 3309, and Kober 5BB can be unambiguously identified; Riparia Gloire and Couderc 1616 can be distinguished from the others, but not from one another; and $\mathrm{SO} 4$ and $5 \mathrm{C}$ also can be distinguished from the others, but not from one another. These results suggest that sequence-specific PCR primers derived from cloned RAPD markers will be useful in typing grape rootstocks.

\section{Literature Cited}

Botta, R., N.S. Scott, I. Eynard, and M.R. Thomas. 1995. Evaluation of microsatellite sequencetagged site markers for characterizing Vitis vinifera cultivars. Vitis 34:99-102.

Bourquin, J.-C., L. Otten, and B. Walter. 1995. PCR-RFLP analysis in Vitis, Ampelopsis and Parthenocissus and its application to the identification of rootstocks. Vitis 34:103-108.

Bourquin, J.-C., A. Sonko, L. Otten, and B. Walter. 1993. Restriction fragment length polymorphism and molecular taxonomy in Vitis vinifera $\mathrm{L}$. Theor. Appl. Genet. 87:431-438.

Bowers, J.E., E.B. Bandman, and C.P. Meredith. 1993. DNA fingerprint characterization of some wine grape cultivars. Amer. J. Enol. Viticulture 44:266-274.

Galet, P. 1979. A practical ampelography. Cornell Univ. Press, Ithaca, N.Y.

Guerra, B. and C.P. Meredith. 1995. Comparison of Vitis berlandieri $\times$ Vitis riparia rootstock cultivars by restriction fragment length polymorphism analysis. Vitis 34:109-112.

Paran, I. and R.W. Michelmore. 1993. Development of reliable PCR-based markers linked to downy mildew resistance genes in lettuce. Theor. Appl. Genet. 85:985-993.

Parfitt, D.E. and S. Arulsekar. 1989. Inheritance and isozyme diversity for GPI and PGM among grape cultivars. J. Amer. Soc. Hort. Sci. 114:486-491.

Striem, M.J., P. Spiegel-Roy, G. Ben-Hayyim, J. Beckmann, and D. Gidoni. 1990. Genomic DNA fingerprinting of Vitis vinifera by the use of multi-loci probes. Vitis 29:223-227.

Subden, R.E., A. Krizus, S.C. Lougheed, and K. Carey. 1987. Isozyme characterization of Vitis species and some cultivars. Amer. J. Enol. Viticulture 38:176-181.

Thomas, M.R., P. Cain, and N.S. Scott. 1994. DNA typing of grapevines: A universal methodology and database for describing cultivars and evaluating genetic relatedness. Plant Mol. Biol. 25:939-949.

Xu, H. 1995. Development of PCR-based markers for identifying grape rootstocks. MS thesis, Oregon State Univ., Corvallis.

$\mathrm{Xu}, \mathrm{H} .$, D.J. Wilson, S. Arulseker, and A.T. Bakalinsky. 1995. Sequence-specific PCR markers derived from RAPD markers for fingerprinting grape (Vitis) rootstocks. J. Amer. Soc. Hort. Sci. 120:714-720.

Yu, J., W.K. Gu, R. Provvidenti, and N.F. Weeden. 1995. Identifying and mapping two DNA markers linked to the gene conferring resistance to pea enation mosaic virus. J. Amer. Soc. Hort. Sci. 120:730-733. 